\title{
Disturbance effect analysis of pipe jacking construction based on failure approach index
}

\author{
Geng Liu ${ }^{1}$, Zhengchun Yang $^{2}$, Huayan Yao ${ }^{1, *}$, Zhenhua Zhang ${ }^{1}$, Jingfeng Wang ${ }^{1}$ \\ ${ }^{1}$ Shool of Civil Engineering, Hefei University of Technology, 23009, Hefei, China \\ ${ }^{2}$ China Water Huaihe Planning, Design and Research Co., Ltd, 230601, Hefei, China
}

\begin{abstract}
In order to evaluate the influence of pipe jacking construction process on ground subsidence and surrounding buildings, the numerical simulation of the construction process was carried out by $\mathrm{FLAC}^{3 \mathrm{D}}$, and the failure approach index (FAI) of the rock and soil around the pipeline was calculated to describe quantitatively their risk and damage state. The numerical results show that the final settlements of the buildings around the pipeline are less than the buildings' safety control values. The rock or soil mass within 0.8 times of the pipe diameter are in the excavation damage zone and disturbance zone $(0.8 \leq \mathrm{FAI} \leq 1.3)$, while outside 0.8 times of the pipe diameter are basically undisturbed $(\mathrm{FAI} \leq 0.8)$.
\end{abstract}

\section{Introduction}

Pipe jacking has become popular in the USA during $1950 \mathrm{~s}^{[1]}$. As a trenchless technology, pipe jacking is widely used in modern municipal pipe networks. Pipe jacking, compared with open cut method, significantly reduces the destruction of city buildings and roads caused by underground pipeline projects, as well as the impact on urban traffic ${ }^{[2]}$. However, there is inevitable disturbance to stratum structure, especially when the environment is very complex, inhomogeneous ground settlement and uneven deformation and crack of ground buildings in the course of pipe jacking construction. Many scholars have done plenty of researches on the basic rules of the stratum structure disturbance and ground settlement caused by pipe jacking constructions ${ }^{[3 \sim 12]}$, but the complex environment and specific engineering requirements are still needed to be considered in detail. Using numerical simulation method, construction process in a complex environment can be simulated according to engineering practice. In the simulation results, the yield states of rock and soil mass can be revealed through plastic zone. But the dangerous level and damage degree cannot be reflected accurately by plastic zone. In order to describe it more intuitively and accurately, Zhang et al. ${ }^{[13 \sim 15]}$ put forward a definition called failure approach index (FAI) and deduced its calculation formulas with several examples to verify the rationality and applicability. Based on FAI, Yao et al. ${ }^{[16]}$ analyzed the stability of soils around shield tunnel during excavation. FAI has the ability to describe quantitatively the dangerous level or

\footnotetext{
*Corresponding author: yaohuayan@hfut.edu.cn
} 
damage degree of soils or rock remaining in the elastic stage before or after its stress state reaches plastic state. Therefore, FAI is capable of providing scientific basis to the evaluation of stability of soil or rock impacted by geotechnical engineering construction.

In this paper, for analyzing the influence of pipe jacking on surroundings more accurately, FLAC3D is used to simulate a pipe jacking construction process. The damage range and degree of the soil around the pipeline is quantified by the FAI index. In addition, combining with the site monitoring data, the influence of pipe jacking on surrounding constructions are also revealed clearly.

\section{Project profile}

The pipe jacking construction technology is applied to the transformation of the rain and sewage pipeline nearby a subway station in Hefei City. The construction environment is complex with many buildings adjacent to the new pipeline. It could be a threat to the safety of nearby buildings and roads if pipe jacking construction induces uneven deformation of ground and foundation.

A rain pipeline of diameter $2.5 \mathrm{~m}$ and a sewage pipeline of diameter $0.8 \mathrm{~m}$ are laid in parallel in the south of a subway station. Two segments of the project are selected to for study in this paper. One is the new 309m long sewage pipeline, and the other is the new $264.7 \mathrm{~m}$ long rain pipeline. The site layout is shown in Figure 1. Soil layers distribution around the two pipelines are shown in Figure 2.

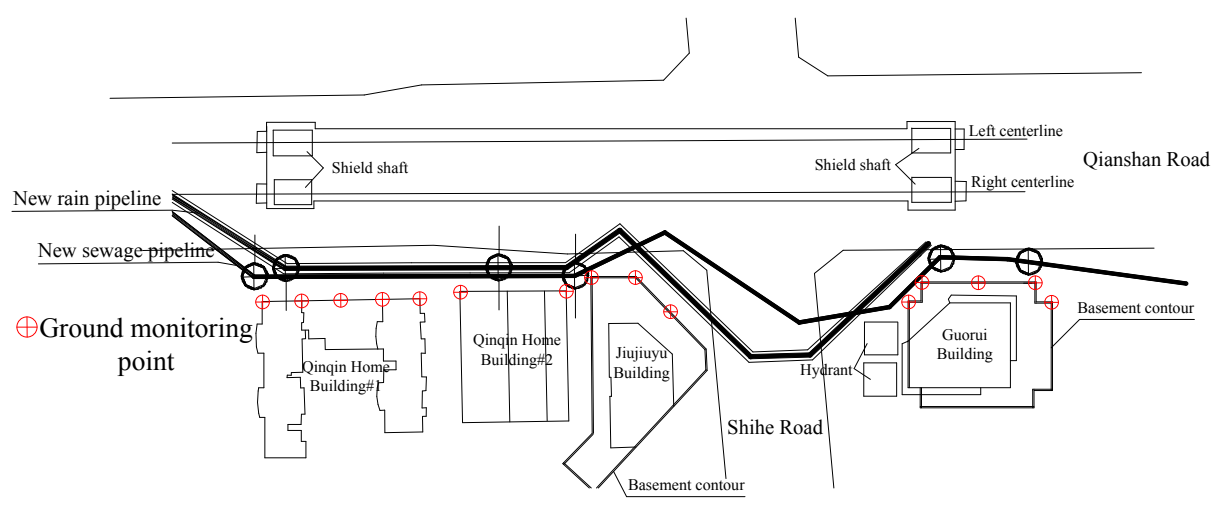

Fig. 1. Site layout

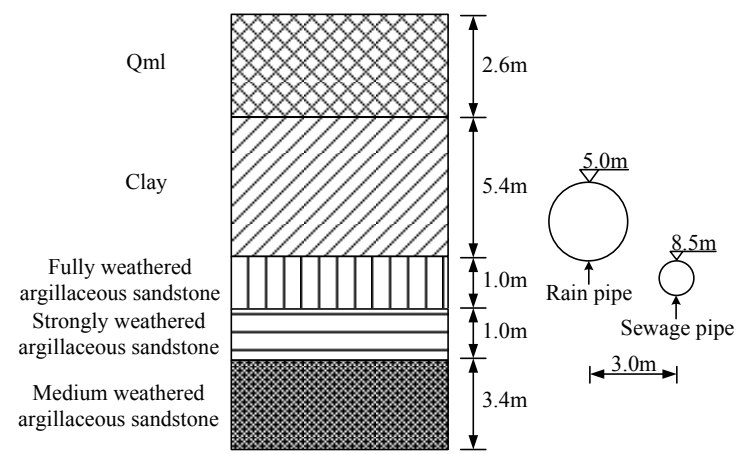

Fig. 2. Typical stratigraphic profile

\section{Failure Approach Index (FAI)}


FAI, a quantitative index, uses a state variable continuous in space to comprehensively evaluate the dangerous level of rock or soil mass under complex stress state. The calculation formula of FAI is:

$$
F A I=\left\{\begin{array}{cl}
\omega & 0 \leq \omega<1 \\
1+F D & \omega=1, F D \geq 0
\end{array}\right.
$$

Where FD $=\bar{\gamma}_{\mathrm{P}} / \bar{\gamma}_{\mathrm{P}}^{\mathrm{r}}, \bar{\gamma}_{\mathrm{P}}$ is plastic shear strain, $\bar{\gamma}_{\mathrm{P}}^{\mathrm{r}}$ is ultimate plastic shear strain of materials, $\omega$ is a phase complementary parameter of YAI, $\omega=1-$ YAI, YAI is yield approach index. The calculation formula of YAI (detailed deduced process is given in reference 7) under Mohr-Coulomb yield criterion is:

$$
Y A I=\frac{\frac{I_{1} \sin \varphi}{3}+\left(\cos \theta_{\sigma}-\sin \frac{\theta_{\sigma} \sin \varphi}{\sqrt{3}}\right) \sqrt{J_{2}}-c \cos \varphi}{\frac{I_{1} \sin \varphi}{3}-c \cos \varphi}
$$

where $I_{1}$ is the first invariant of strain tensor, $J_{2}$ is the second invariant of strain tensor, $\theta_{\sigma}$ is the so-called Lode's angle, $\mathrm{c}$ is cohesion, $\varphi$ is internal friction angle.

Different stress-strain stages can be defined with FAI. Generally, $0 \leq$ FAI $<0.8$, $0.8 \leq \mathrm{FAI}<1.0,1.0 \leq \mathrm{FAI}<2.0$ and FAI $\geq 2.0$ represent low stress region, excavation disturbance region, excavation damage region and failure region, respectively ${ }^{[8]}$.

\section{Numerical simulations}

\subsection{The geometry and boundary conditions}

A three-dimensional numerical model is established in this study based on engineering practice and considering the impact of boundary conditions. The model is $370 \mathrm{~m}$ in length, $190 \mathrm{~m}$ in width and $30 \mathrm{~m}$ in height. It is meshed into eight-node hexahedron elements, as shown in Figure 3. The prescribed displacement boundary conditions are: the bottom surface is fixed, the four sides are set as normal constraint, and the top surface is free in displacement. The building load beside the new pipelines is equivalent to a uniform force of $20 \mathrm{kPa}$ per layer and applied on the base of the buildings.

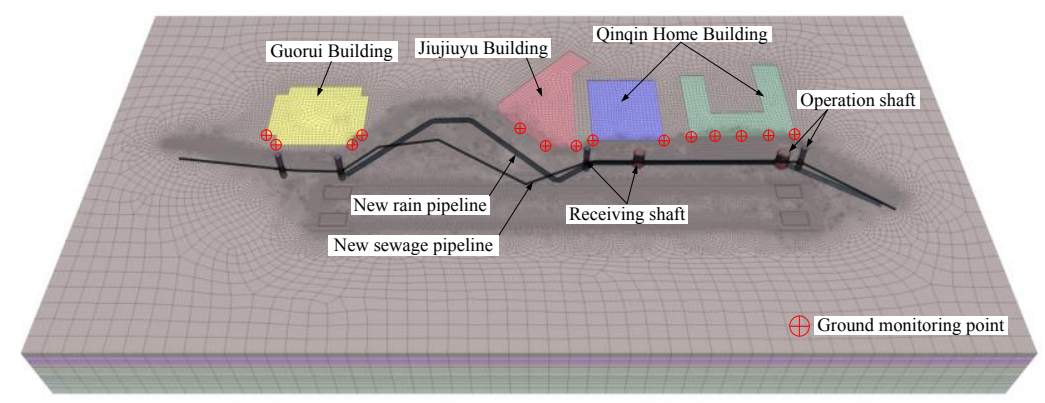

Fig. 3. Layouts of Pipeline and Monitoring Points

\subsection{Constitutive model and yield criterion}

Normally, in low stress state, the stress-strain curve of rock or soil (including grouting material) shows ideal elastic-plastic characteristic, and the yield criterion of rock or soil accords with Mohr-Coulomb Criterion. Therefore, in the process of numerical simulation, ideal elastic-plastic model is chosen as the constitutive model of rock or soil mass, as well 
as the grouting material. The new rain and sewage pipe are made of reinforced concrete, and under the action of earth pressure and other external loads, the stress and deformation of reinforced concrete remain in the elastic stage. So the elastic model is chosen as the constitutive model of the pipe.

\subsection{Material parameters}

According to the engineering geological investigation report and comparing to similar projects, the physical and mechanical parameters of all materials are shown in Table 1.

Table 1. Physical and mechanical parameters of materials

\begin{tabular}{|c|c|c|c|c|c|c|}
\hline $\begin{array}{c}\text { Materials } \\
\text { Category }\end{array}$ & $\begin{array}{c}\text { Elasticity } \\
\text { modulus (MPa) }\end{array}$ & $\begin{array}{c}\text { Poisson's } \\
\text { ratio }\end{array}$ & $\begin{array}{c}\text { Natural unit } \\
\text { weight }\left(\mathrm{kN} / \mathrm{m}^{3}\right)\end{array}$ & $\begin{array}{c}\text { Cohesion } \\
(\mathrm{kPa})\end{array}$ & $\begin{array}{c}\text { Inner friction } \\
\text { angle }\left({ }^{\circ}\right)\end{array}$ & $\begin{array}{c}\text { Tensile } \\
\text { strength }(\mathrm{kPa})\end{array}$ \\
\hline Plain fill & 15 & 0.20 & 19.0 & 15 & 10 & 0 \\
\hline Clay & 40 & 0.30 & 19.8 & 18 & 18 & 0 \\
\hline $\begin{array}{c}\text { Fully weathered } \\
\text { argillaceous sandstone }\end{array}$ & 105 & 0.23 & 18.5 & 30 & 20 & 30 \\
\hline $\begin{array}{c}\text { Strongly weathered } \\
\text { argillaceous sandstone }\end{array}$ & 110 & 0.21 & 20.0 & 40 & 30 & 40 \\
\hline $\begin{array}{c}\text { Medium weathered } \\
\text { argillaceous Sandston }\end{array}$ & 125 & 0.20 & 22.5 & 50 & 45 & 50 \\
\hline Pipe & 30000 & 0.20 & 25.0 & - & - & - \\
\hline Grout & 4 & 0.30 & 23.0 & 15 & 25 & 0 \\
\hline
\end{tabular}

\subsection{Numerical procedure}

Pipe jacking construction is a continuous process. But to facilitate the simulation, it is simplified into a discontinuous step-by-step process. Before the simulation begins, the soil excavation elements, the pipe joint elements and the grouting elements are divided into different groups. It is assumed that the pipe is pushed forward $5 \mathrm{~m}$ each step in the simulation. Before the jacking begins, all the groups of elements are natural rock and soil mass. In the first jacking step, through changing the material parameters of soil or rock within the first $5 \mathrm{~m}$ into those of the pipe joint elements and the grouting elements, the first step of the pipe jacking construction can be simulated. Use the same procedure of the first step to simulate the next step of the pipe jacking process until the entire pipe is laid.

\section{Analysis of simulation results}

\subsection{Settlement of the surface near the pipeline}

The perturbation caused by pipe jacking construction leads to the settlement of surface above the pipeline ${ }^{[17]}$. The settlement area is mainly concentrated in the range of about $12.5 \mathrm{~m}$ from the pipeline, and generally the farther away from the pipeline, the smaller the settlement is. The largest settlement, which is $8.6 \mathrm{~mm}$, appears on the surface right above the pipeline, and it is less than $30 \mathrm{~mm}$ the control value of the ground settlement during construction, as given in Figure 4. The maximum distance between adjacent building and pipeline is about $10 \mathrm{~m}$, and the minimum is about $4 \mathrm{~m}$. That is to say, all the buildings marked in Figure 4 are influenced by the construction. Furthermore, there are different degrees of settlements on the surface close to buildings as shown in Table 2. Table 2 and Figure 5 show that the simulation results and monitoring data in-situ of the final settlement agree well, which indicates that the numerical simulation process is reasonable and reliable.

The simulation results and monitoring data in-situ show that the settlements of 
monitoring point JC-29 with the shortest distance to the pipeline is $2.21 \mathrm{~mm}$. The maximum settlement $2.83 \mathrm{~mm}$ happens in monitoring point JC-33 which is $7.15 \mathrm{~m}$ away from the pipeline. The final settlements of surrounding buildings are less than $3 \mathrm{~mm}$, much less than the safety control value $30 \mathrm{~mm}$. These show that pipe jacking construction have little effect on surrounding buildings. In fact, because of trenchless construction and the timely follow-up of pipes and grouting, pipe jacking hugely reduces the damage to rock and soil around the pipeline, compared with open cut method, so as to ensure the safety of construction.

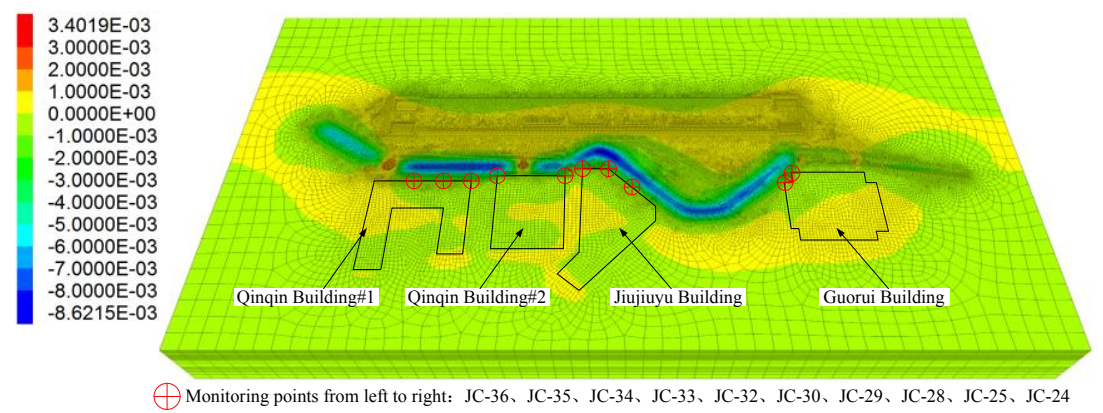

Fig. 4. Overall vertical displacement nephogram

Table 2. Final settlement of monitoring point

\begin{tabular}{|c|c|c|c|c|c|c|c|c|c|c|c|}
\hline \multirow{2}{*}{ Monitoring points } & \multicolumn{3}{|c|}{ Qinqin Building\#1 } & \multicolumn{2}{c|}{ Qinqin Building\#2 } & \multicolumn{2}{c|}{ Jiujiuyu Building } & \multicolumn{2}{c|}{ Guorui Building } \\
\cline { 2 - 11 } & JC-36 & JC-35 & JC-34 & JC-33 & JC-32 & JC-30 & JC-29 & JC-28 & JC-25 & JC-24 \\
\hline $\begin{array}{c}\text { Horizontal distance } \\
\text { to pipeline (m) }\end{array}$ & 9.51 & 9.42 & 9.41 & 7.15 & 6.94 & 4.12 & 4.03 & 4.06 & 5.22 & 5.46 \\
\hline $\begin{array}{c}\text { Simulation results } \\
\text { (mm) }\end{array}$ & 1.17 & 1.54 & 1.52 & 2.83 & 1.47 & 1.58 & 2.21 & 1.62 & 1.02 & 1.37 \\
\hline $\begin{array}{c}\text { Field monitoring } \\
\text { results (mm) }\end{array}$ & 1.23 & 1.67 & 1.63 & 2.92 & 1.40 & 1.60 & 2.01 & 1.55 & 1.12 & 1.37 \\
\hline
\end{tabular}

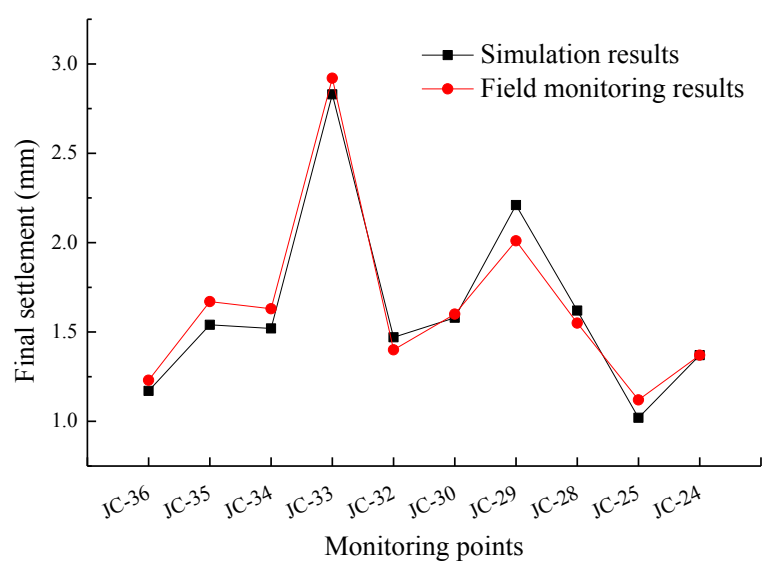

Fig. 5. Vertical displacement of surface monitoring points for building settlement

Taking for example the rain pipeline construction segment between the operation shaft and receiving shaft in Figure 3, making vertical section through the central axis of pipeline, the vertical displacement and the FAI nephogram are shown in Figure 6 and Figure 7. The soil with $0.8 \leq \mathrm{FAI} \leq 1.2$ is distributed within the range of about 0.8 times the pipe diameter above the pipeline, as show in Figure 7. In another word, its most dangerous state still remains in excavation damage region. Near the upper surface of the pipe where the stratum structure disturbance is most severe, the vertical displacement of soil mass reaches 
$12.7 \mathrm{~mm}$. From the positions with 0.8 times of the pipe diameter above the pipeline to the surface, the FAI value of soil mass in this range is around 0.4 , that is to say, pipe jacking construction has little influence on the soil mass in this range, due to being in low stress region.

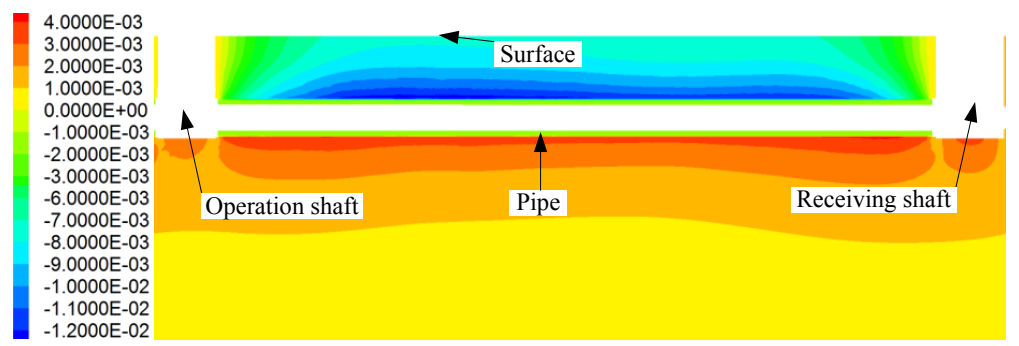

Fig. 6. Vertical Displacement of Longitudinal Section

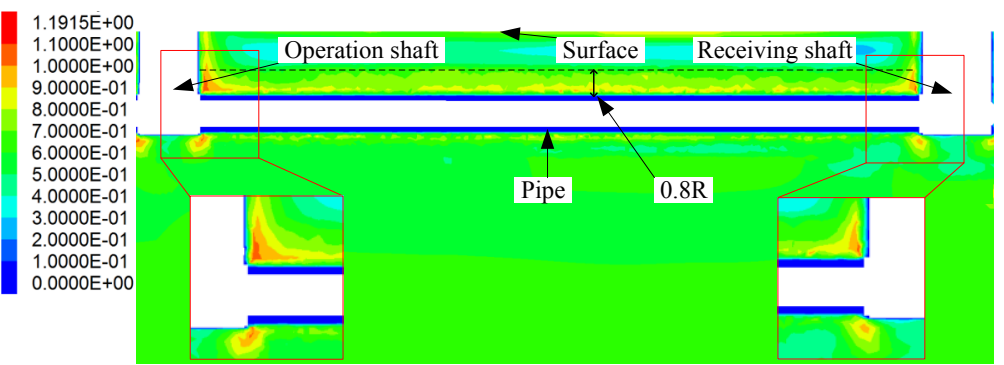

Fig. 7. Failure approach index of Longitudinal Section

\subsection{Influence on surface buildings}

The influence of construction on surrounding buildings can be evaluated through final settlements only at macroscopic deformation level, yet the final settlements can't reflect the dangerous level and damage degree of rock and soil mass during construction. So FAI is adopted for the evaluation. Figure 9 and 10 are tow cross sections of the pipeline through tow monitoring points JC-33 and JC-29, respectively. Monitoring point JC-33 and JC-29 have the largest final settlement values as shown in table 2. Figure 8 is plotted using the final settlements of a series of monitoring points which are arranged equidistantly on the intersecting lines of the surface and tow cross sections JC-33 and JC-29.

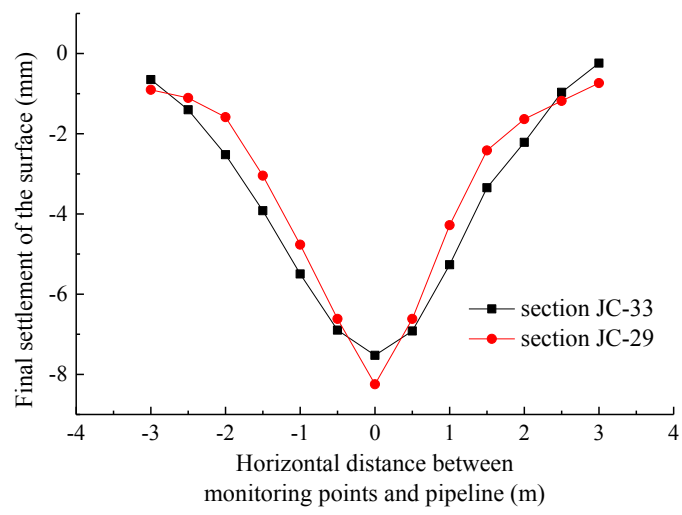

Fig. 8. Subsidence of surface monitoring points perpendicular to pipeline direction

As Figure 9 and 10 showed, distinct deformation area is concentrated in the range of 0.8 times of the pipe diameter near the pipe. And in this area, the rock and soil mass with 
$0.8 \leq \mathrm{FAI} \leq 1.3$ is in excavation disturbance region and excavation damage region, as shown in Figure 11 and 12. It is to say that the stratum structure in this area is affected by construction more seriously than others. The maximum settlement on surface in this area is $8.6 \mathrm{~mm}$. Outside this area, rock and soil mass with $\mathrm{FAI} \leq 0.8$ is hardly affected by construction, and the maximum settlement on surface is $3.1 \mathrm{~mm}$. The building foundations are far away from this area, and there is no obvious change in stress-strain state of the soil near the building foundation. The maximum vertical displacement of the soil near the foundation is about $1 \mathrm{~mm}$. Therefore, pipe jacking construction has little influence on surrounding buildings.

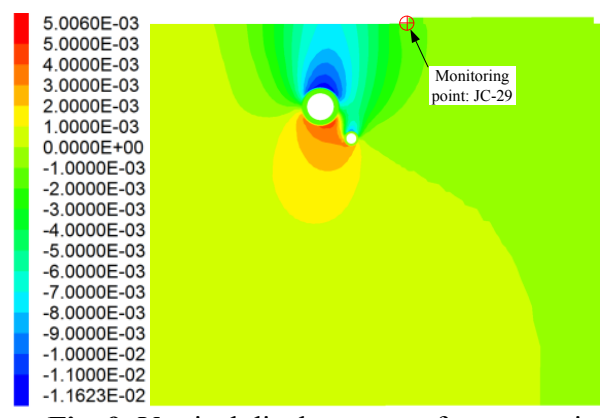

Fig. 9. Vertical displacement of cross section JC-29

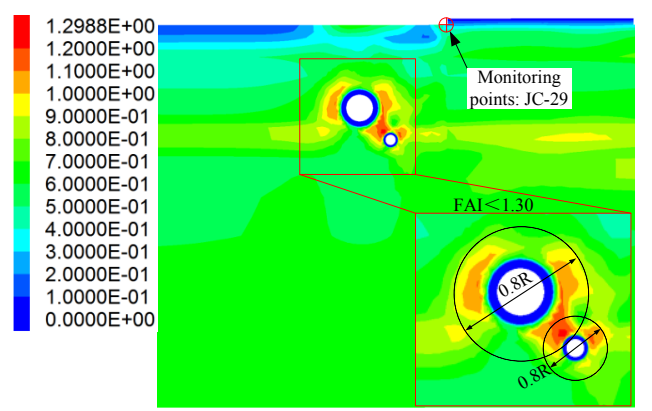

Fig. 11. FAI of cross section JC-29

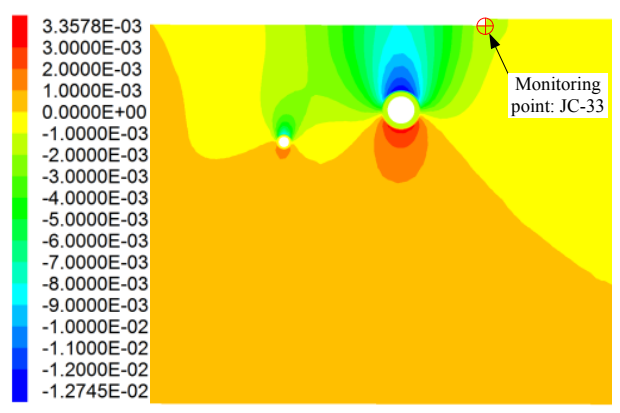

Fig. 10. Vertical displacement of cross section $\mathrm{JC}-33$

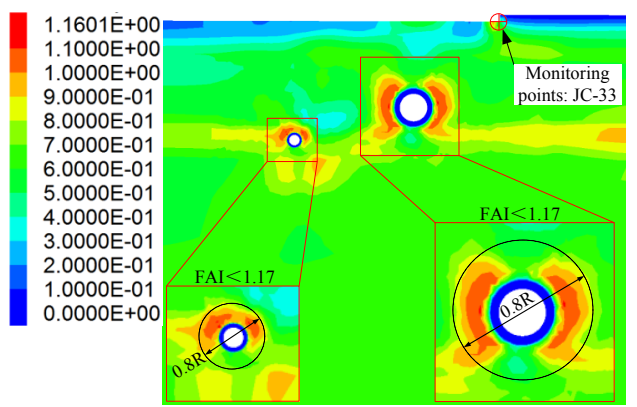

Fig. 12. FAI of cross section JC-33

\section{Conclusion}

Considering the drawback of plastic zone in traditional simulation methods that it is unable to describe the dangerous level of rock or soil mass, FAI is introduced to evaluate the dangerous state of rock and soil mass during pipe jacking construction, so as to provide scientific basis to the evaluation of safety in construction.

By analyzing the FAI of the rock and soil mass around the pipelines, it turns out that the maximum FAI value is less than 1.3, which proves that there is no sever damage during pipe jacking construction. The range of the excavation disturbance region and excavation damage region $(0.8 \leq \mathrm{FAI} \leq 1.3)$ is only within 0.8 times of the pipe diameter away from the pipe surface. The stratum structure in this area is disturbed by construction more seriously than others. The maximum settlement on surface corresponding to the area where $0.8 \leq \mathrm{FAI} \leq 1.3$ is $8.6 \mathrm{~mm}$, less than the safety control value $30 \mathrm{~mm}$. Rock and soil mass near the building foundations with $\mathrm{FAI} \leq 0.8$ is hardly affected by construction because the building foundations are much farther than 0.8 times of the pipe diameter away from the pipe. The maximum vertical displacement is about $1 \mathrm{~mm}$, which is far less than the safety 
control value. Therefore, pipe jacking is a suitable construction method to be adopted to ensure the safety of surrounding foundations and buildings for the pipe laying.

\section{References}

1. R. L. Sterling. Developments and research directions in pipe jacking and microtunneling. Undergr. Sp., (2018)

2. A. I. Sofianos, P. Loukas, C. Chantzakos. Pipe jacking a sewer under Athens. Tunn. Undergr. Sp. Tech., 19(2):193-203 (2004)

3. H. Feng, X. Gong, R. Xu. Finite element analysis of influence of pipe-jacking construction on environments. Chin. J. Rock Mech. Eng., 23(7): 1158-1162 (2004)

4. G. Wei, Z. Y. Huang, R. Q. Xu, et al. Study on calculation methods of ground deformation induced by pipe jacking construction. Chin. J. Rock Mech. Eng., 24(s2): 5808-5815 (2005)

5. F. Li, K. Fang, H. Li. Application of ANSYS 3D FEM in studies of surface deformation caused by pipe jacking. Wuhan Univ. J. Nat. Sci., 12(4):633-637 (2007)

6. C. Li, Z. Zhong, C. Bie, et al. Field performance of large section concrete pipes cracking during jacking in Chongqing-a case study. Tunn. Undergr. Sp. Tech., 82:568-583 (2018)

7. Y. Shao, S. C. Wang, Y. Guan. Numerical simulation of soil squeezing effects of a jacked pipe in soft foundation soil and in foundation soil with an underlying gravel layer. Geotech. Geol. Eng., 34(2):493-499 (2016)

8. C. Li, Z. Zhong, X. Liu, et al. The investigation of ultra-long-distance concrete pipe stuck in quartz sandstone formation using numerical simulation. Arab. J. Geosci., 11:678 (2018)

9. G. Wei, C. L. Chen, J. Y. Yu. Study on calculating methods of soil vertical deformation induced by pipe jacking construction. Rock Soil Mech., 28 (3): 619-624 (2007)

10. Y. G. Fang, H. Mo, C. Zhang. Theoretic and testing analysis of soil deformation in the area of disturbance caused by pipe-jacking. Chin. J. Rock Mech. Eng., 22(4):601-605 (2003)

11. H. M. Zhan. Research on ground deformation caused by pipe jacking construction. Chin. J. Undergr. Sp. Eng., 4(3): 583-585 (2008)

12. F. J. Bing, X. Wang, N. Xi, et al. 3D numerical simulation of pipe jacking and its soil applicability study. Chin. J. Undergr. Sp. Eng., 7 (6):1209-1215 (2011)

13. C. Zhang. Study on method of safety evaluation for rock engineering based on failure approach index. [PhD thesis]. Chinese Academy of Sciences, Wuhan (2006)

14. C. Q. Zhang, H. Zhou, X. T. Feng. Stability assessment of rockmass engineering based on failure approach index. Rock Soil Mech., 28(5):888-894 (2007)

15. C. Q. Zhang, H. Zhou, X. T. Feng. An index for estimating the stability of brittle surrounding rock mass: FAI and its engineering application. Rock Mech. Rock Eng., 44(4):401-414 (2011)

16. H. Yao, X. Shao, Z. Zhang, et al. Hydro-mechanical coupling analysis of shield tunnel based on failure approach index. Chin. J. App. Mech., 33(6):1057-1063 (2016)

17. J. F. Yu. Study on the deformation of earth's surface induced by pipe jacking construction. [PhD thesis], Guangzhou University, Guangzhou (2006) 